\title{
Estudos taxonômicos em Agarista coriifolia (Thunb.) Hook. ex Nied e espécies relacionadas (Ericaceae, Lyonieae): avaliação envolvendo caracteres macro e micromorfológicos
}

\section{$\underline{\text { Ariadne de Araújo Sampaio }}^{1}$, Marcos da Costa Dórea ${ }^{2}$ \& Reyjane P. Oliveira ${ }^{3}$}

1. Bolsista FAPESB, Graduando em Bacharelado em Ciências Biológicas, Universidade Estadual de Feira de Santana, e-mail: ari.biologiauefs@gmail.com

2. Orientador, Departamento de Ciências Biológicas, Universidade Estadual de Feira de Santana, e-mail: mcdorea@uefs.br

3. Departamento de Ciências Biológicas, Universidade Estadual de Feira de Santana, e-mail: rpatricia@uefs.br

PALAVRAS CHAVE: Agarista; taxonomia; palinologia.

\section{INTRODUÇÃO}

A família Ericaceae é representante do clado das Asterídeas, ordem Ericales (APG 2016). Apresenta distribuição cosmopolita, com cerca de 124 gêneros e 4.100 espécies, e é encontrada frequentemente em áreas tropicais e temperadas, habitando áreas ensolaradas e de solo ácidos (Souza \& Lorenzi 2012). No Brasil ocorrem 12 gêneros e 99 espécies, dois eles encontrados na Bahia (Agarista D.Don ex G.Don e Gaylussacia Kunth), com ca. 19 espécies e 13 variedades. Ambos são ocorrentes na Bahia, encontrados ao longo da Chapada Diamantina, especialmente em áreas de campos rupestres (Sampaio e Oliveira 2017).

Agarista está inserido na tribo Lyonieae, subfamília Vaccinioideae (Romão, 2011) sendo registradas 21 espécies desse gênero no Brasil, a maioria em campos rupestres da Cadeia do Espinhaço (Romão \& Souza, 2014). Estudos anteriores realizados por Sampaio \& Oliveira (2017) indicaram a ocorrência de seis espécies e um morfotipo desse gênero

na Chapada Diamantina, cujos aspectos morfológicos não concordavam com nenhuma das referidas espécies, algumas delas com limites confusos, necessitando de reavaliação taxonômica.

Assim, o presente trabalho teve como objetivo principal analisar mais detalhadamente a identidade taxonômica de espécies de Agarista ocorrentes na Chapada Diamantina, especialmente de A. coriifolia (Thunb.) Hook. ex Nied, afim de reavaliar a existência de novos caracteres que auxiliem na delimitação das mesmas, tanto do ponto de vista macro quanto micromorfológico.

\section{METODOLOGIA}

Novas coletas foram realizadas ao longo da Chapada Diamantina, com base na delimitação da SEI (2018) e com a finalidade de tentar observar as plantas em campo e melhor entender suas variações e delimitações. As amostras de ramos férteis coletados foram processadas e incorporadas à coleção do Herbário da Universidade Estadual de Feira de Santana (HUEFS, sigla segundo Thiers 2018), e amostras excedentes de botões florais foram separadas ainda em campo sempre que possível, visando o desenvolvimento de estudos polínicos.

Foram analisados todos os espécimes de Agarista depositados no HUEFS e buscas amplas foram realizadas em bancos de dados de herbários virtuais, tendo em vista a 
atualização da lista do gênero na região, através do SpeciesLink e herbário virtual Reflora. Os nomes aceitos foram revisados através das informações contidas na base de dados do Trópicos, sendo consultados também os materiais tipo de todas as espécies e dos seus sinônimos mais representativos, a fim de subsidiar as identificações. A identificação e a descrição dos materiais de todas as espécies de Agarista da região foi realizada com auxílio de bibliografia especializada (Kinoshita-Gouvêa 1980; Judd 1995; Romão \& Souza 2003; Romão et al., 2004; Silva \& Cervi, 2006; Kinoshita \& Romão, 2012; Mezabarba et al., 2013; Romão \& Souza, 2014; Cabral et al., 2016).

Para as análises polínicas foram obtidos botões florais de 11 amostras herborizadas de seis espécies de Agarista previamente identificadas na região (Sampaio \& Oliveira, 2017). Os botões florais foram dissecados e as anteras submetidas a acetólise (Erdtman, 1960) para posterior análise dos grãos de pólen. Para cada amostra foram montadas quatro lâminas, três com gelatina glicerinada incolor e uma corada com safranina, recobertas com lamínula e seladas com parafina histológica fundida. Usando microscópio óptico, foram medidos 25 grãos de pólen para cada amostra, na posição apical (tetraédrica) e lateral (decussada), sendo tomadas as medidas do diâmetro maior (D) e menor (d) (Modesto \& Melhem 1982). As medidas da exina, sexina e nexina (quando possível) foram feitas em 10 grãos de pólen, usando o lado do apocolpo (LAP) e diâmetro equatorial em vista polar (DEp) para obter o índice da área polar (IAP). A partir das medidas, calculou-se média aritmética (x), desvio padrão (s), desvio padrão da média (sx), coeficiente de variabilidade (CV), intervalo de confiança da média (IC) a 95\%. A terminologia seguida para as descrições foi a de Punt et al. (2007).

\section{RESULTADOS}

Foram analisados 55 espécimes de Agarista presentes no acervo do HUEFS, além de várias outras amostras através de consultas aos herbários virtuais, incluindo materiais tipo de todas as espécies. Foi confirmada a ocorrência de seis espécies desse gênero na Chapada Diamantina, com base em Sampaio e Oliveira (2017): A chapadensis (KinGov.) Judd., A. coriifolia (Thunb.) Hook. ex Nied., A. oleifolia (Cham.) G. Don., A. pulchella (Cham. \& Schltdl) G. Don., A. pulchra Pohl, e A. virgata Judd. Destas, A. coriifolia e A. oleifolia foram as espécies com o maior número de amostras nas coleções consultadas, sendo aparentemente as espécies mais comuns na região. Dos espécimes analisados, 14 ainda encontravam-se identificadas sob Leucothoe D.Don (Sleumer, 1959), gênero que atualmente encontra-se na sinonímia de Agarista com suporte de estudos filogenéticos (Judd 1984), sendo esses materiais corretamente redeterminados.

Dentre os táxons reconhecidos para a Chapada Diamantina por Sampaio \& Oliveira (2017), apenas Agarista sp. não teve análise polínica realizada, devido à ausência de botões florais na exsicata disponível em herbário e também, porque a mesma não foi localizada em campo durante as recentes coletas. Assim, esse morfotipo, mantido à parte por Sampaio (2017), devido às características divergentes em relação todas as espécies supracitadas, ainda não pôde ter sua identidade confirmada.

Quanto às espécies analisadas, Agarista coriifolia, A. pulchra e Agarista oleifolia são as espécies que apresentam maior variação morfológica entre os indivíduos, por esses motivos as análises polínicas envolveram mais que um espécime, oriundos de diferentes localidades. Os grãos de pólen das espécies estudadas podem aparecer nas lâminas em 
vista apical e vista lateral, sendo predominante a vista apical (Fig. 1). Em A. virgata só foi possível visualizar as tétrades em vista lateral. Dentre as espécies analisadas, $A$. coriifolia e A. virgata apresentaram grãos de pólen de tamanho grande, enquanto as demais (A. chapadensis, A. oleifolia, A. pulchlella e A. pulchra) tiveram grãos de pólen de tamanho médio (Tabela 1). Quanto a ornamentação da exina, a maioria foi considerada escabrada e apenas A. oleifollia apresentou-se verrucada,. Também foram observadas diferenças na espessura da exina, sendo A. coriifolia e A. virgata as espécies com exina mais espessas. Desse modo, foi possível verificar que diferenças nos grãos de polén relacionadas ao tamanho, espessura e ornamentação da exina foram importantes para reforçar os limites adotados para essas espécies, especialmente aquelas mais variáveis, a exemplo de A. coriifolia e A. pulchella, que compartilham o mesmo formato da base foliar, mas que apresentam diferenças no diâmetro e na ornamentação da exina.

Tabela 1. Principais caracteres dos grãos de polén de representantes do gênero Agarista na Chapada Diamantina, Bahia. *Faixa de variação (médias \pm desvio padrão).

\begin{tabular}{lccccc}
\hline \multicolumn{1}{c}{ Espécies } & $\begin{array}{c}\text { *Diâmetro maior } \\
(\boldsymbol{\mu m})\end{array}$ & $\begin{array}{c}\text { *Diâmetro menor } \\
(\boldsymbol{\mu m})\end{array}$ & $\begin{array}{c}\text { Exina } \\
(\boldsymbol{\mu m})\end{array}$ & Ornamentação & $\begin{array}{c}\text { IAP } \\
(\boldsymbol{\mu m})\end{array}$ \\
\hline A. chapadensis & $32,5(37,5 \pm 0,4) 45$ & $32,5(36,5 \pm 0,2) 37,5$ & 1,6 & Escabrada & 0,57 \\
A. coriifolia & $44,5(55,5 \pm 0,8) 62,5$ & $45(50,8 \pm 0,5) 55$ & 2,1 & Escabrada & 0,57 \\
A. oleifolia & $32,5(40,5 \pm 0,4) 45$ & $32,5(40,5 \pm 0,4) 45$ & 1,4 & Verrucada & 0,4 \\
A. pulchella & $37,5(41 \pm 0,4) 45$ & $37,5(40,3 \pm 0,4) 45$ & 1,8 & Escabrada & 0,63 \\
A. pulchra & $32,5(42 \pm 0,8) 50$ & $32,5(40,40,7) 45$ & 1,7 & Escabrada & 0,53 \\
A. virgata & $47(51,3 \pm 0,4) 57,5$ & --- & 3,2 & Escabrada & --- \\
\hline
\end{tabular}

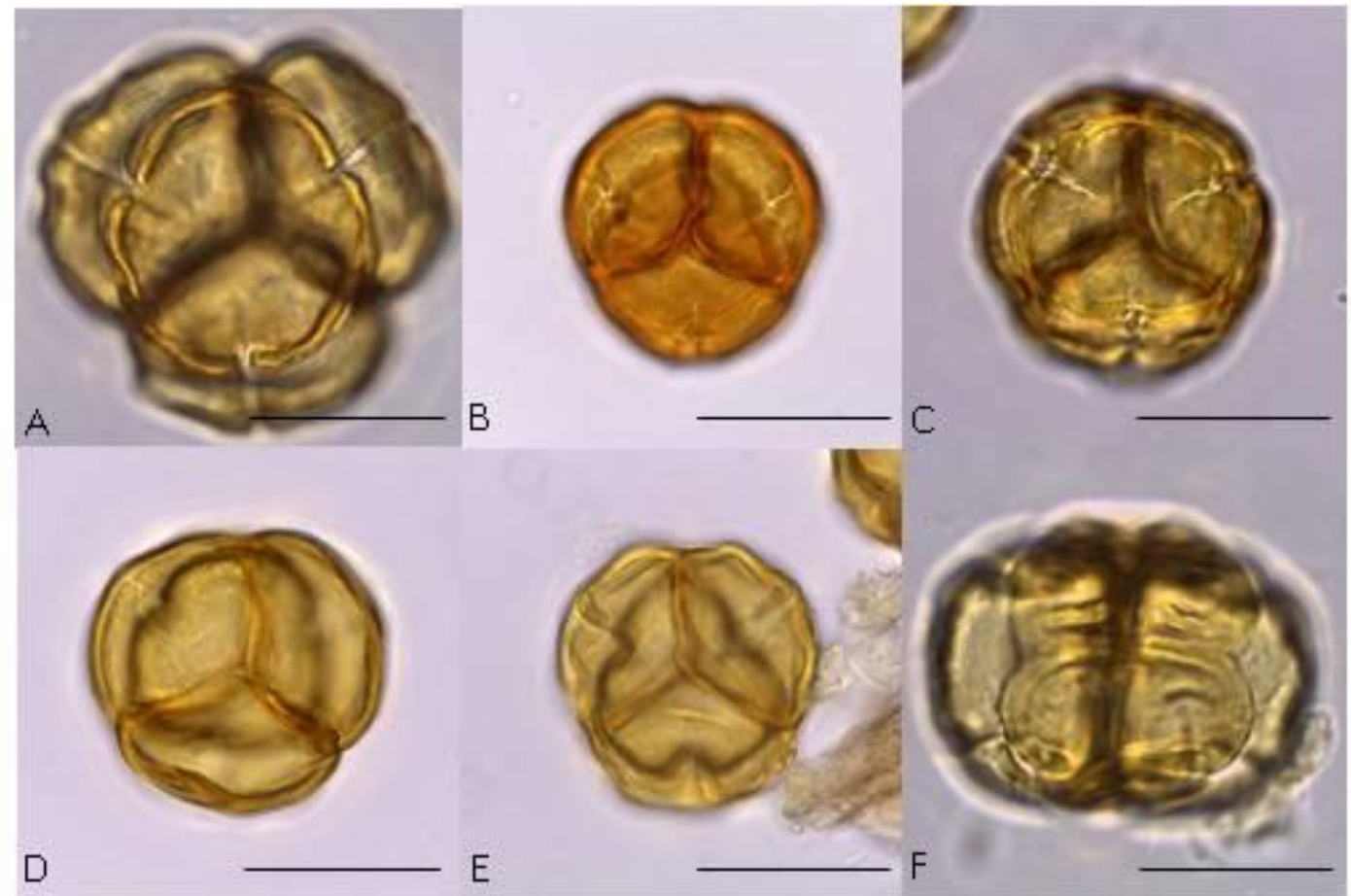

Figura 1. Grãos de pólen encontrados em espécies de Agarista ocorrentes na Chapada Diamantina, Bahia. A - A. coriifolia; B - A. chapadensis; C - A. oleifolia; D - A. pulchella; $\mathbf{E}-A$. pulchra $; \mathbf{F}-A$. virgata. Escala $=20 \mu \mathrm{m}$ 


\section{CONCLUSÕES}

No presente trabalho foram analisados aspectos taxonômicos e polínicos das espécies de Agarista ocorrentes da Chapada Diamantina, com objetivo de melhor compreender os limites entre as espécies, especialmente naquelas mais variáveis. Apenas Agarista sp. não foi analisada, devido à ausência de botões florais para análise. Apesar dos grãos de pólen são serem essencialmente diferentes em cada uma das espécies analisadas, esse trabalho representa um importante avanço para esclarecer a delimitação das mesmas, especialmente em espécies de taxonomia completa como A. coriifolia. Como o estudo foi realizado apenas utilizando microscopia óptica, sugere-se que futuramente técnicas da microscopia eletrônica de varredura também sejam empregadas nesse grupo, especialmente para análise de maiores detalhes na ornamentação dos grãos de pólen.

\section{REFERÊNCIAS}

APG (Angiosperm Phylogeny Group). 2016. An update of the Angiosperm Phylogeny Group classification for the orders and families of Flowering plants: APG IV. Botanical Journal of the Linnean Society 181(1), 1-20.

CABRAL, A., ROMÃO, G.O., ROMAN, S.A. \& MENINI NETO, L. 2016. Ericaceae da Serra Negra, Minas Gerais, Brasil. Rodriguésia 67: 225-236.

ERDTMAN, G. 1960. The acetolysis method. A revised description. Svensk Botanisk Tidskrift, Stockolm 39: 561-564.

JUDD, W.S. 1984. A taxonomic revision of the American species of Agarista (Ericaceae). Journal of Arnold Arboretum 65: 255-342.

KINOSHITA, L. S.\& ROMÃO, G. O. 2012. Flora Fanerogâmica do Estado de São Paulo: Ericaceae. Boletim do Instituto de Botânica de São Paulo 7: 151-172.

KINOSHITA, L.S. \& ROMÃO, G.O. 2015. Ericaceae in Lista de Espécies da Flora do Brasil. Jardim Botânico do Rio de Janeiro. Disponivel em: <http://floradobrasil.jbrj.gov.br/jabot/floradobrasil/FB109>.

KINOSHITA-GOUVÊA, L.S. 1980. Estudos taxonômicos e fitogeográficos da família Ericaceae no Brasil. Tese de Doutorado. Universidade de São Paulo. São Paulo.

MEZABARBA, V., VIANNA FILHO, M. D. M., BORGES, R. A. X., \& MANSANO, V. D. F. 2013. Ericaceae from Parque Nacional do Itatiaia, Rio de Janeiro State, Brazil. Hoehnea 40(1), 115-130.

MODESTO, Z. M. M., \& MELHEM, T. S. 1982. Agarista, Agauria e Leucothoe (Ericaceae): revisao palinotaxonomica.(Agarista, Agauria and Leucothoe genus (Ericaceae): pollen taxonomic revision). Revista Brasileira de Botânica 5(1-2), 83-101.

PUNT, W., HOEN, P.P, BLACKMORE, S., NILSSON, S., LE THOMAS, A. 2007. Glossary of pollen and spore terminology. Review of Palaeobotany and Palynology 143: 1-81.

ROMÃO, G.O. \& SOUZA, V.C. 2014. Flora da Serra do Cipó, Minas Gerais: Ericaceae. Boletim do Instituto de Botânica de São Paulo 32(1): 43-70.

DE ARÁUJO SAMPAIO, A. 2017. Estudos taxonômicos em Ericaceae do Semiárido, com ênfase na Chapada Diamantina. Anais Seminário de Iniciação Científica, (21).

SLEUMER, H. 1959. Studien über die Gattung Leucothoe D. Don. Botaniche Jharbucher Systematik 78(4): $435-480$.

SOUZA, V.C. \& LORENZI, H. 2012. Botânica Sistemática: guia ilustrativo para identificação das famílias de fanerógamas nativas e exóticas no Brasil, baseado em APG II. $3^{\text {a }}$ ed. Nova Odessa, São Paulo, Instituto Plantarum.

THIERS, B. 2018 [continuously updated]. Index Herbariorum: A global directory of public herbaria and associated staff. New York Botanical Garden's Virtual Herbarium. Disponível em: http://sweetgum.nybg. org/science/ih/. Acessado em 30.04.2018. 